\title{
Health Belief Model: Selfcare Penderita Hipertensi di Wilayah Kerja UPT Puskesmas Kalirejo Kabupaten Pesawaran
}

\section{Health Belief Model: Selfcare for Hypertension Patients in the Kalirejo Primary Healtcare, Pesawaran Regency}

\author{
Dhiny Easter Yanti ${ }^{1}$, Agung Aji Perdana², Nina Oktarina ${ }^{1}$ \\ ${ }^{1}$ Fakultas Kesehatan Masyarakat Universitas Malahayati, Lampung, Indonesia \\ 2 Puskesmas Haji Mena, Lampung Selatan, Indonesia \\ *Korespondensi penulis: dhiny.easter@gmail.com
}

Penyerahan: 28-07-2020, Perbaikan: 24-07-2020, Diterima: 23-08-2020

\begin{abstract}
As many as 1.13 million people worldwide suffer from hypertension, the prevalence of hypertension in the world was $22 \%$, where the highest prevalence was in Africa, $27 \%$. The lowest was in America, 18\% (WHO, 2020). In 2019 Hypertension ranks among noncommunicable diseases visiting Puskesmas with 23,276 cases and number two at Pesawaran District Hospital with 972 cases. In 2019 at Kalirejo Community Health Center was the second and highest contagious infectious disease for non-communicable diseases. Selfcare was the main strategy of health promotion at the individual level. It was a shift in philosophy from "(efforts to) cure (disease)" to the philosophy of "care (health"), "especially the control of chronic diseases such as hypertension. Health Belief Model (HBM), a model of individual health behavior consisting of individual beliefs: Perceived Susceptibility, Perceived Severity, Perceived Benefits, Perceived Barrier, perceived self-efficacy together with modifying factors (gender, education level, Etc.) and taking action (behavior individuals) with the assistance of cues to action. This study aimed to determine the relationship of HBM components with hypertensive self-care in the work area of UPT. Kalirejo, Pesawaran Regency, in 2019. This research method was quantitative, with a cross-sectional approach with primary data collection. The sample was 360 respondents. The sampling method was cluster random sampling and then analyzed with chi-square and logistic regression. Results: There was a relationship between hypertension self-care and gender ( $p$-value $<0.001 ; O R=2.6)$, perceived susceptibility ( $p$-value $<0.001 ;$ OR $=3.4$ ), perceived severity ( $p$-value 0.004; OR $=5.1)$, perceived benefit ( $p$-value $<0.001 ; O R=2,3)$, Perceived barrier $(p$-value $<0.001)$, perceived self-efficacy ( $p$-value $<0.001 ; O R=5,4$ ), cues to action ( $p$-value $<0.001 ; O R=$ 2.8 ). The dominant variable related to Selfcare was gender. Suggestion: should increase educational activities in the target group, especially women with hypertension within the Germas (Health Life Movement) and PIS-PK framework (Health Indonesia Program-Family Approach).
\end{abstract}

Keywords: Health Belief Model, Selfcare, Hipertension.

\begin{abstract}
ABSTRAK
Jurnal Dunia Kesmas, Vol. 9 No. 2, April 2020, hal. $192-205$

ISSN 2301-6604 (Print), ISSN 2549-3485 (Online)

http://ejurnalmalahayati.ac.id/index.php/duniakesmas/index
\end{abstract}

Sebanyak 1,13 juta orang di seluruh dunia menderita Hipertensi, prevalensi penderita Hipertensi di dunia adalah 22\%, dimana prevalensi tertinggi berada di Afrika 27\%, dan terendah di Amerika 18\% (WHO, 2020). Pada tahun 2019 Hipertensi merupakan penyakit menular tertinggi dengan 2.630 kasus di Puskesmas Kalirejo. Self-care adalah strategi utama dari promosi kesehatan pada level individu dan merupakan pergeseran filosofi dari 
"(upaya) penyembuhan (penyakit)" menjadi filosofi "peduli (kesehatan)" khususnya pengendalian penyakit kronis seperti Hipertensi. Tujuan penelitian ini untuk mengetahui hubungan komponen HBM dengan self-care Hipertensi di wilayah kerja UPT.Kalirejo Kabupaten Pesawaran. Metode penelitian ini menggunakan desain cross sectional dengan pengambilan data primer. Sampel sebesar 360 responden dan cara pengambilan sampel secara cluster random sampling lalu kemudian dianalisis dengan chi square dan regresi logistik. Terdapat hubungan Self-care Hipertensi dengan jenis kelamin ( $p$-value $<0.001$; OR 2.6), perceived susceptibility ( $p$-value $<0.001$; OR 3.4), perceived severity ( $p$-value 0.004 $\mathrm{OR}=5,1$ ), perceived benefit ( $p$-value $<0.001 ; \mathrm{OR}=2,3$ ), Perceived barrier ( $p$-value $<0.001$;), perceived self-eficacy ( $p$-value $<0.001$; OR 5.4), cues to action ( $p$-value $<0.001$; OR 2.8). Variabel yang dominan berhubungan dengan Self-Care adalah jenis kelamin. Saran: hendaknya meningkatkan kegiatan edukasi pada kelompok sasaran khususnya perempuan penderita Hipertensi dalam kerangka Germas dan PIS-PK.

Kata kunci: Health Belief Model, Selfcare, Hipertensi.

\section{PENDAHULUAN}

Hipertensi merupakan suatu keadaaan dimana tekanan darah sistolik > 140 $\mathrm{mmHg}$ dan atau tekanan darah diastolic $>90 \mathrm{mmHg}$ (Kemenkes RI, 2018). Hipertensi menyumbang 9,4 juta kematian diseluruh dunia setiap tahunnya. Pada tahun 2008 diseluruh dunia sekitar $40 \%$ orang dewasa berusia 25 tahun keatas telah terdiagnosis Hipertensi. Prevalensi Hipertensi tertinggi berada di wilayah Afrika dimana 46\% orang dewasa 25 tahun keatas menderita Hipertensi sedangkan wilayah dengan prevalensi terendah adalah Amerika sebesar 35\% dimana prevalensi wilayah lainnya sebesar 40\%. Prevalensi Hipertensi lebih banyak terjadi pada negara berpenghasilan rendah dibandingkan negara tinggi (WHO, 2013).

Prevalensi Hipertensi di Indonesia berdasarkan diagnosis dokter sebesar $8,36 \%$, penderita Hipertensi sedang minum obat sebesar $8,84 \%$. Prevalensi berdasarkan kelompok umur tertinggi berada pada usia $>75$ tahun sebesar 24,04\%, usia $65-74$ tahun sebesar 23,31\%, usia 55-64 tahun sebesar $18,31 \%$, usia $45-54$ tahun sebesar $12,62 \%$, usia $35-44$ tahun sebesar $5,73 \%$. Proporsi minum obat antiHipertensi pada penduduk usia $>18$ tahun kategori rutin sebesar $54 \%$, tidak rutin sebesar $32,27 \%$, tidak minum obat sebesar $12,89 \%$. Proporsi alasan tidak minum obat sesuai petunjuk adalah sering lupa, obat tidak tersedia, minum obat tradisional, tidak tahan efek samping obat, tidak mampu membeli obat rutin, tidak rutin minum obat, merasa sudah sehat serta alasan lainnya. Proporsi kerutinan mengukur tekanan darah pada penduduk usia $>18$ tahun adalah rutin $12 \%$, kadang-kadang $47 \%$, tidak mengukur $41 \%$ (Kemenkes RI, 2018).

Faktor risiko Hipertensi yang tidak dapat diubah adalah umur, jenis kelamin, keturunan) sedangkan faktor risiko yang dapat diubah adalah kegemukan (obesitas), merokok, kurang aktivitas fisik, konsumsi garam berlebihan, dislipidemia, konsumsi alkohol berlebih, psikososial dan stress. Kebijakan dan strategi Nasional Kemenkes RI mengendalikan Hipertensi diantaranya adalah penurunan faktor risiko, dan deteksi dini (Kemenkes RI, 2013).

Proporsi status gizi pada orang dewasa berdasarkan kategori Indeks Mass Tubuh (IMT) Nasional pada kategori 
Berat Badan (BB) lebih (13,6\%) dan obesitas $(21,8 \%)$. Proporsi merokok pada usia $>10$ tahun dengan kategori perokok saat ini dimana merokok setiap hari $(24 \%)$ terbanyak pada usia 30-34 tahun, kadang-kadang $(4,6 \%)$ terbanyak pada usia 45-49 tahun. Proporsi perilaku konsumsi minuman beralkohol dalam sebulan terakhir pada penduduk $>10$ tahun adalah $3,3 \%$, tertinggi pada umur 20-24 $(6,4 \%)$ (Kemenkes RI, 2018).

Prevalensi Hipertensi yang didiagnosis dokter di Propinsi Lampung pada tahun 2018 (7,95\%). Penderita yang terdiagnosis Hipertensi dan sedang minum obat $(8,49 \%)$, Hipertensi berdasarkan hasil pengukuran $(29,94 \%)$. Proporsi minum obat antiHipertensi kategori rutin $(49,52 \%)$, tidak rutin $(38,9 \%)$ tidak minum obat $(11,58 \%)$ dengan alasan sering lupa $(12,4 \%)$, obat tidak tersedia $(1,7 \%)$, minum obat tradisional $(18,2 \%)$, tidak mampu beli obat rutin $(9,8 \%)$, tidak rutin berobat $(38,1 \%)$, merasa sudah sehat $(62,2 \%)$. Proporsi kerutinan mengukur tekanan darah pada penduduk usia $>18$ tahun adalah rutin $12 \%$, kadangkadang $47 \%$, tidak $41 \%$ (Kemenkes RI, 2018).

Angka Hipertensi yang terdiagnosis oleh tenaga kesehatan di wilayah Kabupaten/Kota di Propinsi Lampung mendapatkan Kabupaten Lampung Barat pada posisi pertama bersama dengan Kabupaten Lampung Utara sebesar $10,2 \%$, sedangkan pada posisi kedua Kabupaten Mesuji dengan angka $8,8 \%$ dan pada posisi ke tiga Lampung Timur dengan angka $8,3 \%$, posisi keempat adalah Tulang Bawang, Kota Bandar Lampung dengan angka $8,2 \%$, disusul Way Kanan sebesar $7,5 \%$ dan pada urutan keenam dari 14 Kabupaten Se-Propinsi
Lampung Pesawaran sebesar 7,4\% (Kementerian Kesehatan, Riskesdas Dalam Angka Propinsi Lampung, 2013).

Data Hipertensi Kabupaten Pesawaran pada Tahun 2016 dan 2017 menduduki urutan ketiga dengan jumlah kasus 14.119, dan 14.856, pada tahun 2018 Hipertensi menduduki urutan kedua dengan 16.054 kasus (Dinas Kesehatan Kabupaten Pesawaran, 2018).

Data Hipertensi di Kabupaten Pesawaran tahun 2016-2018 tertinggi berada di Puskesmas Gedong Tataan sedangkan Puskesmas Kalirejo menduduki urutan kelima. Puskesmas Kalirejo menjadi lokasi penelitian karena belum pernah ada yang meneliti terkait Hipertensi di lokasi ini sebelumnya. Penyakit Hipertensi menempati urutan ketujuh pada 10 besar penyakit di Poli Rawat Jalan dengan jumlah penderita 749 orang $(8,3 \%)$ dan merupakan urutan pertama pada penyakit tidak menular (UPTD Puskesmas Kalirejo, 2018).

Health Belief Model (HBM) atau model kepercayaan kesehatan adalah salah satu model perilaku kesehatan individu (Champion \& Skinner dalam Glanz et al, 2008). Model ini awalnya diterapkan untuk perilaku pencegahan namun diperluas seperti untuk mengidentifikasi korelasi penggunaan layanan kesehatan dan kepatuhan terhadap saran medis (Abraham \& Sheeran dalam Corner \& Norman, 2015), perilaku peran-sakit dan perilaku pemanfaatan layanan kesehatan (Baghianimoghadam et al, 2011).

Self-care adalah perilaku dimana individu melakukan kegiatan promotif, preventif, kuratif dan tindakan rehabilitasi untuk meningkatkan kesehatan mereka (WHO/SEARO, 
1991 dalam WHO, 2009). Selfcare adalah kegiatan yang dilakukan individu, keluarga dan masyarakat dengan niat meningkatkan kesehatan, mencegah penyakit, membatasi penyakit, dan memulihkan kesehatan. Penelitian (Fekhrizadeh et al, 2014) menyatakan terdapat hubungan antara jenis kelamin ( $p$ value 0,011$)$, tingkat pendidikan ( $p$ value 0,003 ), self-efficacy/keyakinan akan kemampuan seseorang melakukan tindakan menghadapi situasi tertentu $(p=0.005)$, perceived barriers (hambatan yang dirasakan) $(p=0.0001)$ dan perceived benefits/manfaat yang dirasakan $(p=0.021)$ dengan self-care Hipertensi, variabel yang paling dominan berhubungan dengan selfcare Hipertensi adalah Self-efficacy. Penelitian (Nadirian et al, 2018) menyatakan perceived barriers $(p=0,000)$, susceptibility/kerentanan yang dirasakan $(p=0,004)$ berhubungan dengan self-care pasien gagal jantung. Penelitian (Baghianimoghadam et al, 2013) mendapatkan hasil terdapat hubungan antara perceived benefit $(p=0,008)$, self efficacy $(p=0,099)$, perceived threat/ancaman yang dirasakan $(p=0,059)$ dengan self-care. Penelitian (Larki et al, 2018) terdapat hubungan antara persepsi kerentangan dengan self-care Hipertensi (Diet rendah garam OR 3,47, perilaku merokok $\mathrm{OR}=1,1)$, keparahan yang dirasakan $(\mathrm{OR}=1,82)$ dengan self-care Hipertensi. Penelitian Mulyati et al (2013) menyebutkan terdapat hubungan antara self efficacy dengan self management behavior dengan $p$ value 0,003 dan OR 3,6. Penelitian (Setiyaningsih et al., 2016) yang mendapatkan hasil terdapat hubungan antara cues to action ( $p$ value 0,005 ), perceived benefit ( $p$ value 0,005 ), perceived barrier ( $p$ value 0,001 ), perceived threat ( $p$ value 0,0001 ) dengan perilaku pencegahan penyakit Hipertensi.

Dari uraian diatas oleh karena itu peneliti tertarik untuk melakukan penelitian dengan judul Health Belief Model: Self-care Penderita Hipertensi di wilayah kerja UPT.Puskesmas Kalirejo Kabupaten Pesawaran Tahun 2019.

\section{METODE}

Jenis penelitian yang dilakukan adalah cross sectional,sampel sebesar 180 orang dengan uji statistik chi square dilanjutkan regresi logistik. Waktu penelitian dilaksanakan pada Agustus 2019. Penelitian ini dilakukan di Wilayah kerja UPT. Puskesmas Kalirejo Kabupaten Pesawaran, yaitu Poli Umum Puskesmas ataupun di Posbindu wilayah kerja UPT.Puskesmas Kalirejo. Pengambilan sampel dilakukan dengan menggunakan teknik cluster random sampling. Data primer diperoleh melalui wawancara peneliti berdasarkan daftar pertanyaan yang diajukan langsung kepada responden, Penelitian dimulai pada bulan Agustus 2019, peneliti dibantu oleh 2 orang enumerator. Analisis data menggunakan univariat, bivariat dengan chi square dan multivariat dengan regresi logistik.

\section{HASIL}

Responden kasus yang berpartisipasi dalam penelitian memiliki berjenis kelamin perempuan $(52,3 \%), \%)$, tingkat pendidikan rendah $(72,5 \%)$, memiliki Self-Care tinggi $(56,7 \%)$, perceived susceptibility (kerentanan yang dirasakan) tinggi sebesar $(55,3 \%)$, perceived severity (tingkat keparahan yang dirasakan) tinggi 
sebesar $(69,2 \%)$, perceived benefit (manfaat yang dirasakan) tinggi sebesar $(61,4 \%)$, Perceived barrier (hambatan yang dirasakan) rendah sebesar $(51,9 \%)$, perceived selfeficacy (keyakinan akan kemampuan untuk melakukan tindakan menghadapi situasi tertentu) tinggi sebesar $(52,2 \%)$, Cues to action (isyarat untuk bertindak) tinggi sebesar $(69,2 \%)$.

Tabel 1. Analisis Bivariat

\begin{tabular}{llrrrr}
\hline Variabel & Kategori & \multicolumn{2}{c}{ Literasi Kesehatan } & P-value & OR (95\% \\
\cline { 3 - 4 } & & $\begin{array}{c}\text { Tinggi } \\
\text { n(\%) }\end{array}$ & $\begin{array}{c}\text { Rendah } \\
\mathbf{n}(\%)\end{array}$ & & (\%) \\
\hline Jenis kelamin & Perempuan & $130(67,7)$ & $62(32,3)$ & 0,000 & 2,6 \\
& Laki-laki & $74(44,0)$ & $94(56,0)$ & & $(1,7-4,0)$ \\
Pendidikan & Tinggi & $57(57,6)$ & $42(42,4)$ & 0,924 & \\
& Rendah & $147(56,3)$ & $114(43,7)$ & & \\
Perceived & Tinggi & $139(69,8)$ & $60(30,2)$ & 0,000 & 3,4 \\
susceptibility & Rendah & $65(40,4)$ & $96(59,6)$ & & $(2,2-5,2)$ \\
Perceived & Tinggi & $171(68,7)$ & $78(31,3)$ & 0,004 & 5,1 \\
severity & Rendah & $33(29,7)$ & $78(70,3)$ & & $(3,1-8,4)$ \\
Perceived Benefit & Tinggi & $143(64,7)$ & $78(35,3)$ & 0,000 & 2,3 \\
Perceived & Rendah & $61(43,9)$ & $78(56,1)$ & & $(1,5-3,6)$ \\
Barriers & Rendah & $70(37,4)$ & $117(62,6)$ & 0,000 & 0,1 \\
Self Efficacy & Tinggi & $134(77,5)$ & $39(22,5)$ & & $(0,1-0,22)$ \\
& Tinggi & $142(75,2)$ & $46(24,5)$ & 0,000 & 5,4 \\
cues to action & Rendah & $62(36,0)$ & $110(64,0)$ & & $(3,4-8,6)$ \\
& Tinggi & $161(64,7)$ & $88(35,3)$ & 0,000 & 2,8 \\
& Rendah & $43(38,7)$ & $68(61,3)$ & & $(1,8-4,5)$ \\
\hline
\end{tabular}

Tabel 2. Analisis Multivariat

\begin{tabular}{lccrr}
\hline \multicolumn{1}{c}{ Variabel } & p-value & OR & \multicolumn{2}{c}{$\mathbf{9 5 \%}$ CI } \\
\hline Jenis Kelamin & 0,000 & 8,233 & 4,242 & 15,976 \\
Perceived severity & 0,000 & 6,521 & 3,372 & 12,608 \\
Perceived benefit & 0,000 & 0,130 & 0,050 & 0,338 \\
Perceived barrier & 0,000 & 0,043 & 0,016 & 0,112 \\
Perceived self efficacy & 0,000 & 4,404 & 2,310 & 8,397 \\
Cues to action & 0,002 & 3,136 & 1,530 & 6,428 \\
\hline
\end{tabular}

Berdasarkan permodelan multivariat terakhir yang dominan berhubungan dengan Self-Care yaitu Jenis kelamin $(\mathrm{OR}=8,2)$, Perceived severity (tingkat keparahan yang dirasakan) $(\mathrm{OR}=6,5)$, perceived self efficacy $(O R=4,4)$, Cues to action $(\mathrm{OR}=3,1)$, Perceived Benefit $(\mathrm{OR}=0,1)$ dan Perceived Barrier $(\mathrm{OR}=0,04)$ dimana variabel yang paling dominan berhubungan dengan Self-Care adalah jenis kelamin serta variabel perceived susceptibility sebagai variabel confounder dari selfcare (perubahan OR $>10 \%$ ).

\section{PEMBAHASAN}

Jenis Kelamin

Penelitian ini mendapatkan hasil bahwa terdapat hubungan antara jenis kelamin dengan Self-Care ( $p$ value $=0,000 \quad \mathrm{OR}=2,6)$ dan hipotesis Ho gagal ditolak. 
Teori yang mendukung hipotesa ini adalah jenis kelamin adalah faktor resiko mutlak Hipertensi yang tidak dapat dirubah (Kementerian Kesehatan RI, 2013). Hu et al, (2013) menyatakan penelitian di Amerika utara dan Eropa Barat menyatakan jenis kelamin adalah salah satu prediktor faktor dalam Self-Care pasien Hipertensi.

Hasil penelitian ini serupa dengan penelitian (Fekhrizadeh et al, 2014) yang mendapatkan hasil terdapat hubungan antara jenis kelamin ( $p$ value 0,011 ) dengan self-care penderita Hipertensi di Iran. Begitu pula penelitian (Poormuhamad \& Jalili, 2017) yang menyatakan Self-Care berhubungan dengan jenis kelamin. Penelitian Motlagh et al. (2016) mendapatkan juga hasil yang serupa dimana jenis kelamin (perempuan) berhubungan dengan Self-Care Hipertensi seperti aktivitas fisik (OR $=0.716)$, perilaku tidak merokok (OR $=1.503)$, diet rendah garam $(\mathrm{OR}=$ 1.497) dan kepatuhan minum obat $(\mathrm{OR}=1.435)$.

Analisis peneliti berdasarkan fakta yang ditemukan di lapangan jenis kelamin perempuan lebih peka dan peduli terhadap kesehatan dibanding pria karena wanita mengalami masalah kesehatan yang lebih kompleks seperti menstruasi, kehamilan, melahirkan, memiliki anak, menopouse dan juga wanita di budaya timur tidak terpapar dengan perilaku kurang baik seperti merokok dan minum alkohol.

\section{Pendidikan}

Penelitian ini mendapatkan hasil bahwa tidak terdapat hubungan antara pendidikan dengan Self-Care ( $p$ value $=0,924$ ) dan hipotesis Ho gagal ditolak.
Teori yang mendukung hipotesa ini pendapat Ajzen (2005) dalam Manuntung (2018) yang menyatakan perilaku individu terhadap suatu hal dipengaruhi oleh tiga faktor latar belakang, salah satunya yaitu faktor sosial yaitu tingkat pendidikan.

Hasil penelitian ini serupa dengan hasil penelitian $\mathrm{Hu}$ et al (2013) yang menyatakan tidak ada hubungan pendidikan dengan Self-Care Hipertensi. Hasil penelitian ini berbeda dengan penelitian hasil (Fekhrizadeh et al, 2014) yang mendapatkan hasil terdapat hubungan antara tingkat pendidikan ( $p$ value 0,003 ) dengan self-care penderita Hipertensi di Iran. Analisis peneliti berdasarkan fakta yang ditemukan responden di UPT.Puskesmas Kalirejo, responden dalam penelitian ini tidak dipilih berdasarkan tingkat pendidikannya melainkan dipilih secara random sampling, sehingga didapatkan responden berpendidikan rendah/pendidikan dasar 261 $(72,5 \%)$.

Perceived susceptibility

Penelitian ini mendapatkan hasil bahwa terdapat hubungan antara perceived susceptibility (kerentanan yang dirasakan) dengan Self-Care ( $p$ value $=0,000 \quad \mathrm{OR}=3,4)$ dan hipotesis Ho ditolak.

Teori yang mendukung hipotesa ini individu yang percaya bahwa mereka memiliki risiko yang rendah terhadap penyakit lebih mungkin untuk melakukan tindakan yang tidak sehat, dan individu yang memandang memiliki risiko tinggi mereka akan lebih mungkin untuk melakukan perilaku untuk mengurangi risiko terserang penyakit (Onoruoiza, 2015). Perceived Susceptibility adalah evaluasi kecenderungan akan masalah 
kesehatan tertentu, jika merasa lebih berisiko atau rentan terkena masalah kesehatan maka akan mempersepsikan penyakit tersebut sebagai ancaman dan akan mengambil langkah tertentu (Flahive et al, 2006). Perceived Susceptibility adalah keyakinan tentang kemungkinan mendapatkan penyakit/kondisi tertentu seperti peluang/resiko kemungkinan menjadi sakit karena Hipertensi, kemungkinan terjadi pengulangan menjadi sakit kembali. Perceived Susceptibility bercirikan tiga tahap yaitu tahap pertama melibatkan kesadaran bahwa ancaman kesadaran bahwa ancaman kesehatan ada, tahap kedua keterlibatan untuk menentukan seberapa berbahayanya ancaman itu dan seberapa banyak orang yang kemungkinan akan berpengaruh. Tahap ketiga adalah ketika ancaman telah dipersonalisasi, kerentanan pribadi akan diakui (Abraham \& Sheeren dalam Conner \& Norman, 2015).

Hasil penelitian ini serupa dengan penelitian (Nadirian et al, 2018) menyatakan perceived susceptibility/kerentanan yang dirasakan $(p=0,004)$ berhubungan dengan self-care pasien gagal jantung. Begitu pula dengan hasil penelitian (Larki et al, 2018) terdapat hubungan antara persepsi kerentangan dengan self-care Hipertensi Diet rendah garam (OR 3,47 )

Analisis peneliti berdasarkan fakta yang ditemukan responden di UPT.Puskesmas Kalirejo perceived susceptibility (kerentanan yang dirasakan) tinggi sebesar $249(69,2 \%)$ karena yang dipilih menjadi respponden adalah pasien telah terdiagnosa oleh dokter mengalami
Hipertensi sejak 6 bulan sebelumnya dan berusia $>30$ tahun, artinya responden telah menyadari bahwa dirinya sudah terkena penyakit Hipertensi dan merasa dirinya sudah melewati batas rentan dan masuk ke dalam kategori penderita penyakit Hipertensi. Susceptibility merupakan representasi individu atas kondisi kesehatannya.

\section{Perceived severity}

Penelitian ini mendapatkan hasil bahwa terdapat tidak hubungan antara perceived severity (tingkat keparahan yang dirasakan) dengan Self-Care $(p$ value $=0,000 \quad O R=5,1)$ dan hipotesis Ho gagal ditolak.

Teori yang mendukung hipotesa ini menurut (Flahive et al, 2006) keseriusan akan masalah kesehatan yang diderita akan membuat individu mempertimbangkan seberapa parah penyakit dan konsekuensi/dampak medis dan sosial yang mungkin dialami jika individu memutuskan untuk mengatasi penyakit tersebut atau membiarkankan penyakit tersebut. Jika merasa penyakit tersebut adalah hal yang serius, mereka akan mempersepsikan sebagai ancaman lebih mungkin melakukan tindakan preventif atau kuratif.

Hasil penelitian ini serupa dengan penelitian (Larki et al, 2018) terdapat hubungan antara Keparahan yang dirasakan $(O R=1,82)$ dengan selfcare Hipertensi.

Analisis peneliti berdasarkan fakta yang ditemukan responden di UPT.Puskesmas Kalirejo persepsi keparahan yang dirasakan tergantung dari kategori tekanan darah yang terjadi apakah masuk ke dalam pre Hipertensi (tekanan darah sistolik 120-139 $\mathrm{mmHg}$ atau tekanan darah 
diastolik $80-90 \mathrm{mmHg}$ ) ataukah masuk Hipertensi tingkat 1 (tekanan darah sistolik $140-159 \mathrm{mmHg}$ atau tekanan darah diastolik $90-99 \mathrm{mmHg}$ ) atau tingkat 2 (tekanan sistolik $>160$ $\mathrm{mmHg}$ dan tekanan diastolik $>100$ $\mathrm{mmHg}$ ). Perceived severity merupakan representasi individu atas kesehatannya. Jika merasa Hipertensi adalah penyakit yang serius dan mengancam jiwa, dapat menyebabkan kesakitan, kecacatan, kematian, ataupun dapat mengganggu pekerjaan dan peran sosial lainnya maka individu akan mencari pengobatan, melakukan perilaku yang dianjurkan untuk mengelola Hipertensinya.

\section{Perceived benefit}

Penelitian ini mendapatkan hasil bahwa terdapat hubungan antara perceived benefit (manfaat yang dirasakan) dengan Self-Care ( $p$ value $=0,000 \quad \mathrm{OR}=2,3)$ dan hipotesis Ho ditolak.

Teori yang mendukung hipotesa ini adalah Perceived benefit yang terdiri dari manfaat medis dan psikososial dalam perilaku yang meningkatkan kesehatan (Abraham \& Sheeren dalam Conner \& Norman, 2015). Manfaat yang didapat misalnya terkait pengelolaan faktor risiko Hipertensi yang dapat dirubah seperti menghindari kegemukan dengam menjaga berat badan agar selalu ideal, berhenti merokok, melakukan aktifitas fisik, mengurangi konsumsi garam berlebihan, mencegah dislipidemia, tidak mengkonsumsi alkohol dan mengelola stress (Kemenkes RI, 2013).

Hasil penelitian ini serupa dengan hasil penelitian (Fekhrizadeh et al, 2014) menyatakan terdapat hubungan antara perceived benefits/manfaat yang dirasakan $(p=0.021)$ dengan self-care Hipertensi. Begitu pula hasil penelitian (Baghianimoghadam et al, 2013) mendapatkan hasil terdapat hubungan antara perceived benefit $(p=0,008)$ dengan self-care. Penelitian (Setiyaningsih et al., 2016) perceived benefit ( $p$ value 0,005$)$ dengan perilaku pencegahan penyakit Hipertensi.

Analisis peneliti berdasarkan fakta yang ditemukan responden di UPT.Puskesmas Kalirejo perceived benefit merupakan keyakinan menyangkut manfaat atau kemanjuran perilaku kesehatan yang disarankan untuk mengelola penyakit Hipertensinya misalnya manfaat yang dirasakan jika patuh minum obat Hipertensi, mengurangi konsumsi karbohidrat, gula, garam maka tekanan darah akan terkontrol, kebiasaan mengkonsumsi makan buah sayur, melakukan aktifitas fisik, olahraga, menjaga berat badan agar ideal, tidak merokok dan tidak mengkonsumsi alkohol maka individu akan mendapatkan manfaat kesehatan sekaligus manfaat sosial (dapat menjalankan perannya dalam masyarakat) dan keuntungan secara finansial.

\section{Perceived barrier}

Penelitian ini mendapatkan hasil bahwa terdapat hubungan antara Perceived barrier (hambatan yang dirasakan) dengan Self-Care ( $p$ value $=0,000 \quad \mathrm{OR}=0,1)$ dan hipotesis Ho ditolak.

Teori yang mendukung hipotesa ini adalah hambatan terdiri atas hambatan praktis untuk melakukan perilaku (misal waktu, biaya, ketersediaan, transportasi, waktu tunggu, biaya psikologis terkait untuk melakukan perilaku tersebut, rasa sakit, rasa malu yang ditimbulkan, 
ancaman terhadap kesejahteraan hidup, gaya hidup dan mata pencaharian (Abraham \& Sheeren dalam Conner \& Norman, 2015).

Hasil penelitian ini serupa dengan hasil penelitian (Fekhrizadeh et al, 2014) menyatakan terdapat hubungan perceived barrier $s$ (hambatan yang dirasakan $)(p=0.0001)$ dengan selfcare Hipertensi. Begitu pula hasil penelitian (Nadirian et al, 2018) menyatakan perceived barrier $s$ $(p=0,000)$ berhubungan dengan selfcare pasien gagal jantung serta penelitian (Setiyaningsih et al., 2016) yang mendapatkan hasil terdapat hubungan antara perceived barrier ( $p$ value 0,001 ) dengan perilaku pencegahan penyakit Hipertensi.

Analisis peneliti berdasarkan fakta yang ditemukan Self-Care baik karena di UPT.Puskesmas Kalirejo perceived barrier merupakan keyakinan menyangkut hambatan untuk melaksanakan perilaku kesehatan yang disarankan untuk mengelola penyakit Hipertensinya. perceived barrier merupakan penilaian individu seberapa besar rintangan untuk mengadopsi atau melakukan tindakan yang disarankan. Suatu tindakan bisa saja tidak diambil oleh seseorang yang sudah memiliki Hipertensi, meskipun individu tersebut percaya terhadap keuntungan mengambil tindakan untuk mengelola penyakit tersebut. Hal ini bisa saja disebabkan oleh hambatan yang dirasakan seperti tindakan pengelolaan Hipertensi dirasakan merepotkan, mahal, tidak menyenangkan, mengganggu kenyamanan sehingga individu menghindari atau menjauh dari tindakan pengelolaan Hipertensi.

Perceived self-eficacy
Penelitian ini mendapatkan hasil bahwa terdapat hubungan antara akses perceived self-eficacy (keyakinan akan kemampuan untuk melakukan tindakan menghadapi situasi tertentu dengan Self-Care ( $p$ value $=0,000$ or $=5,4$ ) dan hipotesis $\mathrm{Ho}$ ditolak.

Teori yang mendukung hipotesa ini adalah Bandura (1994) dalam Manuntung (2018) menjelaskan bahwa self efficacy akan mempengaruhi empat proses dalam diri manusia, yaitu cara individu berpikir (kognitif), perasaan (afektif), motivasional, dan seleksi terhadap perilaku perawatan yang dipilih oleh individu. Self efficacy akan mempengaruhi cara seseorang untuk berpikir, perasaan, motivasi, dan penampilan yang ditunjukkan individu. Motivasi seseorang untuk menunjukkan perilaku tertentu tergantung pada kemampuan individu mengevaluasi self efficacy yang dimilikinya.

Self efficacy individu yang semakin baik akan memudahkan individu dalam memecahkan masalah. Individu yang meyakini bahwa dia mampu melakukan suatu perilaku tertentu akan melakukan perilaku tersebut, sedangkan individu dengan self efficacy yang kurang cenderung untuk tidak melakukan perilaku tersebut atau menghindarinya. Individu dengan self efficacy yang baik akan lebih mudah mengadopsi perilaku baru. Teori Health Belief Model (HBM) Edberg (2010) dalam Manuntung (2018) bahwa seseorang yang telah mendapatkan informasi dan keterampilan terkait dengan penyakitnya akan mempunyai persepsi yang baik pula terhadap penyakitnya dan akan membentuk dan memperkuat self efficacy 
seseorang sebelumnya. Bosworth (2009) bahwa tingkat self efficacy yang baik dapat menyebabkan peningkatan self management untuk memperbaiki kontrol Hipertensi. Self efficacy dapat digunakan sebagai prediktor untuk mengetahui kepatuhan pasien dalam Self-Care behavior. Pasien dengan kepatuhan yang kurang mempunyai self efficacy yang kurang juga. Pasien Hipertensi dengan self efficacy yang baik menunjukkan ketaatan dalam manajemen Hipertensi daripada pasien yang self efficacy-nya kurang dan nilai self efficacy berhubungan dengan perilaku spesifik dalam penatalaksanaan Hipertensi, seperti manajemen berat badan, diet, dan pengobatan.

Hasil penelitian ini serupa dengan penelitian (Fekhrizadeh et al, 2014) menyatakan terdapat hubungan antara self-efficacy/keyakinan akan kemampuan seseorang melakukan tindakan menghadapi situasi tertentu $(p=0.005)$ dengan self-care Hipertensi. Penelitian (Baghianimoghadam et al, 2013) mendapatkan hasil terdapat hubungan antara self efficacy $(p=0,099)$ dengan self-care begitu pula enelitian Mulyati et al (2013) menyebutkan terdapat hubungan antara self efficacy dengan self management behavior dengan $p$ value 0,003 dan OR 3,6.

Hasil penelitian ini berbeda dengan hasil penelitian Manuntung (2018) yang menyatakan tidak ada hubungan antara keyakinan diri dan aktivitas mandiri pasien Hipertensi ( $P$ value $=0,647$ ).

Analisis peneliti berdasarkan fakta yang ditemukan responden di UPT.Puskesmas Kalirejo Self efficacy yang baik akan membuat responden merasa mampu dan yakin untuk melakukan perilaku mandiri terkait perawatan mandiri (Self-Care behavior) Hipertensi karena sudah memiliki pengalaman menjadi penderita Hipertensi 6 bulan sebelumnya misalnya terkait patuh minum obat, mengurangi konsumsi gula garam karbohidrat, makan buah sayur, menjaga berat badan agar ideal, berolahraga, menjauhi asap rokok dan tidak minum minum beralkohol sehingga dapat menurunkan komplikasi Hipertensi dan meningkatkan kualitas hidupnya. Self efficacy yang dimiliki dapat digunakan untuk memprediksi perilaku sehat, jika individu berfikir mereka pasti akan berhasil melakukan perilaku pengelolaan Hipertensi yang dianjurkan maka keberhasilan perubahan gaya hidupan diprediksi akan berhasil.

\section{Cues to action}

Penelitian ini mendapatkan hasil bahwa terdapat hubungan antara cues to action (isyarat untuk bertindak) dengan Self-Care ( $p$ value $=0,000$ dan $\mathrm{OR}=2,8$. dan hipotesis Ho ditolak.

Teori yang mendukung hipotesa ini adalah cues to action adalah diberikan peringatan atau kewaspadaan tentang peningkatan masalah kesehatan potensial apakah akan di tangani dengan melakukan aksi nyata tertentu. Cues to action dapat mengaktifkan perilaku kesehatan ketika kepercayaan kesehatan yang tepat dipegang. Isyarat ini termasuk beragam pemicu, seperti persepsi individu terhadap gejala, pengaruh sosial, dan kampanye pendidikan kesehatan (Abraham \& Sheeren dalam Conner \& Norman, 2015).

Hasil penelitian ini serupa dengan penelitian Yue et al., (2015) yang menyatakan bahwa cues to action 
atau isyarat bertindak berhubungan dengan kepatuhan minum obat antiHipertensi ( $p=0.034)$, begitu pula hasil penelitian (Setiyaningsih et al., 2016) yang mendapatkan hasil terdapat hubungan antara cues to action ( $p$ value 0,005 )

Analisis peneliti berdasarkan fakta yang ditemukan responden di UPT.Puskesmas Kalirejo cues to action berupa layanan, konsultasi terkait penyakit Hipertensi seperti keberadaan Posbindu di setiap desa, cues to action yang berasal dari dalam diri sendiri seperti berupa isyarat fisiologis penyakit Hipertensi (keluhan seperti nyeri belakang kepala, pusing) ataupun isyarat dari eksternal (seperti peristiwa kerabat yang sakit, mengalami stroke karena Hipertensi atau bahkan kematian, informasi dari orang terdekat misalnya berkata bahwa individu terlihat tidak sehat karena penyakitnya atau dari penyedia layanan kesehatan dokter dan puskesmas tentang pentingnya kontrol pada penderita Hipertensi) mendorong individu melakukan SelfCare Hipertensi.

\section{Multivariat}

Berdasarkan permodelan multivariate terakhir terdapat 6 variabel yang dominan berhubungan dengan SelfCare yaitu Jenis kelamin $(\mathrm{OR}=8,2)$, Perceived severity (tingkat keparahan yang dirasakan) $(\mathrm{OR}=6,5)$, perceived self efficacy $(O R=4,4)$, Cues to action $(\mathrm{OR}=3,1)$, Perceived Benefit $(\mathrm{OR}=0,1)$ dan Perceived Barrier $(\mathrm{OR}=0,04)$ dimana variabel yang paling dominan berhubungan dengan Self-Care adalah jenis kelamin.

Teori yang mendasari adalah pendapat faktor sosiodemografi diyakini memiliki efek tidak langsung pada perilaku dengan memengaruhi persepsi kerentanan, keparahan, manfaat, dan hambatan (Champion \& Skinner dalam Glanz et al, 2008). Seorang perempuan saat sudah mengalami menopouse dan kadar hormon estrogen dalam tubuh menurun maka akan lebih rentan terkena Hipertensi, sehingga walaupun jumlah kematian laki-laki dan perempuan akibat stroke hampir sama, di usia muda lebih banyak lakilaki yang terkena stroke. Sementara itu, di usia tua lebih banyak perempuan yang terkena stroke. Stroke didominasi usia tua, tetapi presentase usia 40 tahun ke bawah semakin tahun semakin meningkat (Wibawa, 2018).

Hal ini berbeda dengan hasil penelitian (Fekhrizadeh et al, 2014) yang menyatakan variabel yang paling dominan berhubungan dengan selfcare Hipertensi adalah Self-efficacy. Penelitian Poormuhamad \& Jalili (2017) menyatakan variabel peceived self efficacy $(\beta=0,382)$ merupakan variabel HBM yang paling berhubungan dengan perilaku SelfCare. Penelitian Nadrian et al (2018) menyatakan variabel HBM yang dominan berhubungan dengan SelfCare adalah perceived barrier $\mathrm{s}(\beta=$ $0.315)$ and susceptibility $(\beta=0.165)$. Analisis peneliti berdasarkan fakta yang ditemukan dilapangan jenis kelamin adalah variabel yang paling dominan berhubungan dengan selfcare Hipertensi adalah jenis kelamin karena sebagai salah satu status sosial yang akan mempengaruhi komponen kognitif seseorang. Perempuan dalam menjalani siklus hidupnya saat menstruasi, hamil, melahirkan, menopouse dan perempuan secara peran penanggung jawab utama kesehatan keluarga sehingga selalu 
berhubungan/pemanfaatan layanan kesehatan di semua institusi kesehatan misalnya posyandu, posbindu, Bidan Praktek Swasta, Puskemas Induk ataupun Puskesmas Pembantu serta dengan adanya program Indonesia Sehat-Pendekatan Keluarga (PIS-PK) yang salah satunya berlokasi di wilayah kerja UPT.Kalirejo. Perempuan menimbang pro dan kontra suatu tindakan/perilaku kesehatan, mengkaji keuntungan yang akan didapat jika melakukan suatu perilaku kesehatan tertentu. Setiap individu mempunyai cara yang berbeda dalam mengambil tindakan untuk menyembuhkan gangguan kesehatan yang dirasakan. Semua tergantung pada belief (pengetahuan tentang masalah keseahtan dan persepsi individu tentang gejala penyakit yang dirasakan) masing-masing individu apakah bersedia mengakses layanan kesehatan yang sudah disediakan. Health Belief Model sebagai kerangka berfikir untuk menjelaskan perubahan dan mempertahankan perilaku kesehatan, cara pandang dalam menjelaskan, memprediksi dan intervensi perilaku kesehatan tertentu, misalnya apakah individu memiliki banyak keuntungan dengan melakukan tindakan mengelola faktor risiko Hipertensi, apakah dengan mengelola faktor risiko Hipertensi membantu individu menjalani hidup sebagai seorang penderita Hipertensi tetap sehat dan produktif, mengelola faktor risiko Hipertensi membuatya terhindar dari risiko komplikasi Hipertensi.

\section{KESIMPULAN}

Terdapat hubungan jenis kelamin, tingkat Pendidikan, perceived susceptibility (kerentanan yang dirasakan), perceived severity (tingkat keparahan yang dirasakan), perceived benefit (manfaat yang dirasakan), Perceived barrier (hambatan yang dirasakan), perceived self-eficacy (keyakinan akan kemampuan untuk melakukan tindakan menghadapi situasi tertentu, Cues to action (isyarat untuk bertindak) dengan Selfcare Hipertensi. Variabel jenis kelamin paling dominan berhubungan dengan Self-care Hipertensi.

\section{SARAN}

Agar puskesmas lebih memprioritaskan kelompok sasaran perempuan melalui kegiatan KIE: penyuluhan khususnya topik Hipertensi serta melakukan gerakan masyarakat hidup sehat (Germas) dengan melibatkan semua komponen masyarakat dalam kerangka PIS-PK, mulai dari pendataaan perencanaan hingga tindak lanjut agar didapat data valid terkait penyakit tidak menular khususnya Hipertensi, mengaktifkan kegiatan UKBM khususnya Posbindu diseluruh desa dengan melibatkan masyarakat khususnya kelompok perempuan. Mempromosikan keberadaan Posbindu dalam setiap kegiatan UKBM yang ada di masyarakat.

\section{DAFTAR PUSTAKA}

Aaronson \& Ward. (2010). At a Glance Sistemm Kardiovaskular. (R. Astikawati, Ed.) (Ketiga). Jakarta: Erlangga Medical Series.

Abraham \& Sheeran. (2016). The Health Belief Model. Research Gate. dalam https://www.researchgate.net/pu blication/290193215

Corner \& Norman. (2015). Predicting and Changing Health Behavior Research and Practice With Social 
Cognitive Model. Third Edition. Mc Graw Hill Open University Press. New York USA

Baghianimoghadam et al. (2013). Application of the Health Belief Model in Promotion of Self-Care in Heart Failure Patients. Acta Medica Iranica, 51(1), 52-58.

Cragg, L., Davies, M., \& Macdowall, W. (2013). Health Promotion Theory (Second Edi). Ney York: Mc Graw Hil, Openl University Press.

Dalimartha et al. (2008). Care Your Self Hipertensi. Jakarta: Penebar Plus+. diunduh 4 Maret 2019 dari https://books.google.co.id/books?i $\mathrm{d}=7 \mathrm{IY}$ mDwAAQBAJ\&printsec $=$ fron tcover\&dq $=$ Hipertensi\&hl=en\&sa $=$ X\&ved=0ahUKEwiZxJa9ooThAhXD dysKHeUsAtEQ6AEIWzAH\#v=onep age $\& q=$ Hipertensi\&f $=$ false

Daulay, F. (2015). Uji Validitas Konstruk Pada Instrumen Health Belief Model (HBM) Dengan Metode Confirmatory Factor Analysis (CFA). UGM Repository, (April 2015).

Dinas Kesehatan Kabupaten Pesawaran. (2018). Profil Kesehatan Kabupaten Pesawaran.

Fekhrizadeh et al. (2014). A Survey on Health Beliefs Relation with SelfCare Practice among the Elderly Hypertension in Iran 2013. Bulletin of Environment, Pharmacology and Life Sciences, 3(August), 189-196.

Glanz et al. (2008). Health Behavior and Health Education, Theory, Research and Practice. (C. T. Orleans, Ed.) (Edisi keem). San Fransisco: Jossey-Bass a Wiley Imprint.

Harvin, L. A. (2018). Bridging the Gap: The Use of a Faith Based Intervention to Improve the Management of Hypertension among African Americans. DNP Project submitted to the Department of Nursing of Salisbury University. Salisbury University.

Hastono, S. P. (2016). Analisis Data Pada Bidang Kesehatan. Jakarta: Raja Grafindo.

$\mathrm{Hu}$ et al. (2013). Prevalence Rates of Self-Care Behaviors and Related Factors in

a Rural Hypertension Population: A Questionnaire Survey. Hindawi Publishing Corporation International Journal of Hypertension Volume 2013, Article ID 526949, 8 pages http://dx.doi.org/10.1155/2013/5 26949

Kemenkes RI. (2013). Pedoman Teknis Penemuan dan Tatalaksana Hipertensi. Direktorat Pengendalian Penyakit Tidak Menular Subdit Pengendalian Penyakit Jantung dan Pembuluh Darah. Jakarta: Kementerian Kesehatan Republik Indonesia. https://doi.org/10.1016/j.jash.20 16.08.006

Kemenkes RI. (2013). Riskesdas Dalam Angka Propinsi Lampung, Jakarta.

Kemenkes RI. (2018). Laporan Nasional RISKESDAS 2018. Jakarta.

Larki et al. (2018). Factors Predicting Self-Care Behaviors among Low Health Literacy Hypertensive Patients Based on Health Belief Model in Bushehr District, South of Iran. Hindawi International Journal of Hypertension. diunduh 4Maret 2019 dari https://www.hindawi.com/journal s/ijhy/2018/9752736/ 
Manuntung (2018) Hubungan keyakinan diri dan aktivitas perawatan mandiri pasien Hipertensi di wilayah kerja Puskesmas Pahandut Kola Palangkaraya Raya.

Jurnal Ilmu Kesehatan Vol. 7 No. 1, Nopember 2018. hal 199-209.

Mulyati et al, (2013). Analisis Faktor yang mempengaruhi self Management Behavior pada Pasien Hipertensi. Jurnal Keperawatan Universitas Pajajaran Volume 1 Nomor 2 Agustus 2013

Motlagh et al. (2016). Self-Care Behaviors and Related Factors in Hypertensive Patients. Iran Red Crescent Med J. 2016 June; 18(6):e35805. doi: 10.5812 /ircmj.35805

Nadirian et al. (2018). Cognitive determinants of self-care behaviors among patients with heart failure: A path analysis. Health Promotion Perspectives, 8(4), 275-282. https://doi.org/10.15171/hpp.201 8.39

Onoruoiza SI, Musa, Umar BD, Kunle (2015). Using Health Beliefs Model as an Intervention to Non Compliance with Hypertension Information among Hypertensive Patient. IOSR Journal Of Humanities And Social Science (IOSR-JHSS), 20(9):V

Poormuhamad \& Jalili, (2017). Related factors to self-care behaviors in elderly with hypertension based on the Health Belief Model in Uremia Country. Journal of Gerontology (JOGE). Volume 2 issue 1 Halaman 41-50.DOI 10.29252/joge.2.1.41

Rachmat, M. (2012). Buku Ajar Biostatistika Aplikasi pada Penelitian Kesehatan. Jakarta:
EGC.

Sarafino, E. P., \& Smith, T. W. (2011). Health Psychology, Biopsychosocial Interactions (Seventh Ed). United States of America: Jhon Wiley\& Sons,Inc.

Setiyaningsih et al. (2016). Health Belief Model: Determinan of Hypertension Behavior in Adult at Community Health Center Sukoharjo, Central Java. Journal of Health Promotion and Behavior https://doi.org/10.26911/thejhpb. 2016.01.03.03

UPTD Puskesmas Kalirejo. (2018). Profil UPT. Puskesmas Kalirejo.

Wibawa, (2018). Sampai Usia 40-an Perempuan lebih kebal Stroke dibanding Laki-Laki. kompas.com. $27 \quad$ Februari 2018. https://sains.kompas.com/read/2 018/02/27/070600623/sampaiusia-40-an-perempuan-lebihkebal-stroke-dibanding-laki-laki

WHO. (2009). Self-care in the Context of Primary Health Care, Report of the Regional Consultation Bangkok, Thailand, 7-9 January 2009.

WHO. (2013). A global brief on Hypertension Silent Killer, Global Public Health Crisis. WHO. Jenewa.

Yue et al. (2015). Application of the Health Belief Model to Improve the Understanding of Antihypertensive Medication adherence among chinese patiens. Pub Med NCBI journal 